\title{
5HT6 Antagonists in the Treatment of Alzheimer's Dementia: Current Progress
}

\author{
Megan Andrews · Babak Tousi · Marwan N. Sabbagh
}

Received: February 15, 2018 / Published online: May 2, 2018

(C) The Author(s) 2018

\section{ABSTRACT}

Alzheimer's disease is an important condition with a considerable and unmet disease burden in large need of continued research and more treatment options. The 5HT6 antagonists are a new class of medications to be offered. Because they are pro-cholinergic, these medications are to be used as adjuncts to acetylcholinesterase inhibitors (such as donepezil), further increasing acetylcholine in the central nervous system (CNS). Early trials of the 5HT6 antagonists showed improvements in cognition and activities of daily living when used as adjuncts to current therapies for Alzheimer's dementia. However, recent phase III trials have failed to

Enhanced content To view enhanced content for this article go to https://doi.org/10.6084/m9.figshare. 5986927.

M. Andrews

Creighton University School of Medicine, Phoenix, AZ, USA

B. Tousi

Cleveland Clinic, Lou Ruvo Center for Brain Health, Cleveland, $\mathrm{OH}$, USA

M. N. Sabbagh

Department of Neurology, Barrow Neurological Institute, Phoenix, AZ, USA

M. N. Sabbagh $(\bowtie)$

Cleveland Clinic, Lou Ruvo Center for Brain Health, Las Vegas, NV, USA

e-mail: Sabbagm@ccf.org show a statistically significant improvement in cognitive function. This article will provide a comprehensive review of 5HT6 antagonists in drug development, including some that have been recently discontinued. We will discuss both the successes and failures of this drug class and provide rationale for their continued research and development.

Keywords: 5HT6 Antagonist; Alzheimer's disease; Cognition; Learning; Memory; Mood disorders

\section{INTRODUCTION}

Alzheimer's disease is a progressive neurodegenerative disorder affecting over 40 million people worldwide [1]. It is the most common form of dementia, and there is currently no cure. With the number of elderly increasing each year, Alzheimer's dementia is a wellknown and important disease in desperate need of new treatment options.

The current treatment approach has been used for over a decade [2], offering a temporary (months) and modest improvement in cognition. These medications include acetylcholinesterase inhibitors (donepezil, rivastigmine, galantamine) and NMDA receptor antagonists (memantine) [3]. Acetylcholinesterase inhibitors are meant to increase 
the amount of acetylcholine in the brain by preventing degradation of the neurotransmitter, thus improving cognitive function [4]. Memantine blocks the NMDA receptor on glutamate neurons in conditions of excess glutamatergic stimulation, Alzheimer's disease being a condition of excessive glutamate stimulation leading to neurotransmitter dysfunction [3]. Memantine therefore stabilizes glutamate neurons [5].

The cholinergic hypothesis of Alzheimer's disease postulates that destruction of cholinergic neurons in the CNS leads to decreased acetylcholine and declining cognitive function. By protecting cholinergic neurons and increasing the amount of circulating acetylcholine in the CNS, cognition improves, albeit temporarily. The cholinergic hypothesis does not account for the accumulation of beta-amyloid plaques or neurofibrillary tangles [4]. It also accounts for only one neurotransmitter, acetylcholine, which provides too narrow an approach for such a complex CNS disease.

New research in Alzheimer's dementia has focused on the 5HT6 receptor, a serotonin receptor found primarily in the CNS and localized in areas important in learning and memory. Selective serotonin re-uptake inhibitors have been the main pharmacological treatment for depression and anxiety for the past two decades, but target a different serotonin receptor subtype. 5HT6 antagonists are meant to serve as symptomatic treatment for Alzheimer's disease. These drugs block the 5HT6 receptor, which leads to a decrease in striatal GABA interneurons. This decrease in inhibitory GABA allows for increases in the release of acetylcholine and glutamate [6].

These drugs are likely to be taken in combination with acetylcholinesterase inhibitors to further increase the amount of acetylcholine centrally. Because the 5HT6 receptors are located in the CNS, peripheral side effects are minimal [5]. As they are serotonin receptor antagonists, 5HT6 antagonists may have the added benefit of a positive effect on depression and anxiety, mood disorders often associated with the progression of Alzheimer's disease [6].

Several classes of disease-modifying drugs, including monoclonal antibodies, gamma-secretase inhibitors, tau-aggregation inhibitors, symptomatic treatments such as neurochemical enhancers, and Dimebon, have been evaluated but have not shown any demonstrable efficacy for Alzheimer's disease. Here we discuss the class of 5HT6 antagonists. We highlight their successes and failures and provide rationale for their continued research and development.

This article is based on previously conducted studies and does not contain any studies with human participants or animals performed by any of the authors.

\section{Medications}

The following sections discuss each 5HT6 antagonist and its current state in drug development.

\section{Phase I}

\section{PRX-07034}

PRX-07034 is a selective 5HT6 receptor antagonist. Phase I trials showed PRX-07034 to be highly selective for 5HT6 receptors over other 5HT receptors and non-serotonin receptors. It has similar brain penetration to other 5HT6 antagonists. In rats, PRX-07034 at 1 and $3 \mathrm{mg} / \mathrm{kg}$ was found to enhance delayed alternation, a measurement of improved short-term memory. At the same doses, it also enhanced switch strategy, a measurement of improved cognitive flexibility [7]. There were no adverse effects. No phase II trials have been reported yet [6]. Notable side effects include decreased food intake and body weight, making it a drug candidate for use in obesity as well as Alzheimer's dementia [8].

\section{AVN-322}

AVN-322 is a selective 5HT6 receptor antagonist manufactured by Avineuro Pharmaceuticals for use in cases of Alzheimer's disease and schizophrenia. It is a sister drug to AVN-101 and AVN-211, two 5HT6 antagonists under development for Alzheimer's disease. Phase I trials showed AVN-322 to be well tolerated with no adverse effects. It showed high selectivity for the 5HT6 receptor and reversed the negative cognitive effects of scopolamine and MK-80 [9]. No phase II trials have been reported yet. 


\section{Phase II}

\section{$A V N-101$}

AVN-101 is considered a multitarget serotonin antagonist. It blocks the $5 \mathrm{HT} 7$ serotonin receptor and, to a lesser extent, the 5HT6, 5HT2A, 5HT2C, H1, and adrenergic receptors. AVN-101 is unique to the 5HT6 antagonist drug class in that it exhibits dual 5HT6 and 5HT7 antagonism. These receptors share the same signal transduction pathway and both are present in brain regions important to learning, memory, and anxiety. Phase I trials showed no adverse effects for doses of up to $20 \mathrm{mg} /$ day. The drug will start phase II trials for Alzheimer's disease and anxiety [10].

AVN-101 was developed as a multimodal drug in light of evidence that many serotonin antagonists targeting a single receptor have failed to show clinical efficacy. AVN-101 is being researched primarily as a treatment for Alzheimer's dementia, but has shown significant anxiolytic properties in mice undergoing elevated plus-maze, elevated platform, and open field platform experiments [10]. The progression of Alzheimer's disease is associated with the development of anxiety, depression, and sleep disorders, so AVN-101 may offer the additional benefit of symptomatic relief from these associated mood disorders. This also makes it a good drug candidate for further research into mood disorders [10].

\section{AVN-211 (synonym: CD-008-0173)}

AVN-211 is a selective 5HT6 antagonist originally developed for use in schizophrenia. Phase I trials showed AVN-211 to be well tolerated, with a notable side effect of decreased body weight at $20 \mathrm{mg} / \mathrm{kg}$ [11]. Avineuro Pharmaceuticals has discussed plans to begin clinical trials for its use in Alzheimer's disease after phase II trials for schizophrenia showed positive effects on cognition. Pre-clinical trial data show AVN211 to have pro-cognitive effects superior to those of PRX-07034 and intepirdine in the passive avoidance test and the Morris water maze test. Its effects were comparable to those of donepezil and memantine [11]. AVN-211 has also been shown to have anxiolytic properties in animals undergoing elevated plus-maze, elevated platform, and open field tests [11]. This makes AVN-211 a good drug candidate for future research into mood disorders.

\section{SAM-760 (synonyms: PF-05212377, WYE- 103760)}

SAM-760 is a selective 5HT6 antagonist. It was developed as a follow-up drug to cerlapirdine after cerlapirdine failed to show clinical efficacy at any dose in phase II trials [6]. SAM-760 completed phase I trials with no adverse effects at doses of up to $50 \mathrm{mg}$ daily. Pfizer terminated a phase II trial after SAM-760 $30 \mathrm{mg}$ /day failed to produce an improvement in cognition in patients already taking a stable dose of donepezil. This was an 18-week, randomized, doubleblind, placebo-controlled, parallel assignment study [12]. Development of SAM-760 has since been discontinued. ${ }^{1}$

\section{Phase III}

\section{Idalopirdine (synonyms: Lu AE58054, SGS518, LY483518)}

Idalopirdine is a 5HT6 receptor antagonist originally developed for use in schizophrenia. After showing a positive effect on cognition, the drug was entered into clinical trials for use in Alzheimer's dementia. By blocking the 5HT6 receptor, idalopirdine acts to increase the amount of acetylcholine in the CNS. It further increases the amount of acetylcholine by inhibiting CYP206, an enzyme involved in the metabolism of donepezil, thereby increasing its bioavailability [13].

Idalopirdine completed phase I trials with no adverse effects and showed promising results in a randomized, double-blind, placebo-controlled phase II study. In this 6-month trial, idalopirdine $90 \mathrm{mg}$ daily was taken with donepezil $10 \mathrm{mg}$ daily. This regime showed a significant improvement in cognitive function as measured by ADAS-cog, thereby meeting the phase II

\footnotetext{
${ }_{1}$ More information can be found in the entry "RIP: serotonin receptor 5-HT6 antagonist" on the ALZFORUM website: 2018. https://www.alzforum.org/ news/research-news/rip-serotonin-receptor-5-ht6antagonist. Accessed 10 Feb 2018.
} 
Table 1 Phase III Idalopirdine studies

\begin{tabular}{llll}
\hline Trial & Formulation & Adjunct & Result \\
\hline STARSHINE & Idalopirdine $30 \mathrm{mg}$ & Donepezil & Fail \\
& Idalopirdine $60 \mathrm{mg}$ & Donepezil & Fail \\
STARBEAM & Idalopirdine $10 \mathrm{mg}$ & Donepezil & Fail \\
& Idalopirdine $30 \mathrm{mg}$ & Donepezil & Fail \\
STARBRIGHT & Idalopirdine $30 \mathrm{mg}$ & Acetylcholinesterase inhibitor & Fail \\
& Idalopirdine $60 \mathrm{mg}$ & Acetylcholinesterase inhibitor & Fail \\
\hline
\end{tabular}

trial's primary endpoint. Secondary endpoints, including ADLs and global cognitive status, showed improvement, although these were not statistically significant. ${ }^{2,3}$

Based on the phase II results, a phase III program was started in 2013 which included three randomized, double-blind, placebo-controlled, parallel-group, 24-week trials. These studies include STARSHINE, STARBEAM, and STARBRIGHT, all of which measured the effect of adding idalopirdine to an acetylcholinesterase inhibitor [14] (Table 1). Phase III trials showed weak efficacy as compared to phase II trials, which may be explained by underdosing. Phase II trials evaluated the use of $90 \mathrm{mg}$ daily (30 mg TID) as an adjunct to an acetylcholinesterase inhibitor. Study investigators decided to lower the dose of idalopirdine in phase III trials based on receptor occupancy analysis conducted by PET scan [15].

STARSHINE included one arm of idalopirdine $30 \mathrm{mg}$ daily and a second arm with $60 \mathrm{mg}$ daily, both as adjuncts to donepezil. STARBEAM included two arms of idalopirdine added to donepezil: one arm at $10 \mathrm{mg}$ daily and the second arm at $30 \mathrm{mg}$ daily. STARBRIGHT also included two arms, $30 \mathrm{mg}$ and $60 \mathrm{mg}$, of idalopirdine as an adjunct to an acetylcholinesterase

\footnotetext{
${ }^{2}$ More information can be found in the entry for idalopirdine on the ALZFORUM website: https://www. alzforum.org/therapeutics/idalopirdine. Accessed 10 Feb 2018.

3 Please see the press release from Lundbeck A/S: "Lundbeck's Lu AE58054 meets primary endpoint in large placebo-controlled clinical proof of concept study in people with Alzheimer's disease" http://investor. lundbeck.com/releasedetail.cfm?ReleaseID=677436. Accessed 9 Mar 2018.
}

inhibitor (donepezil, rivastigmine, or galantamine). As reported by Atri et al., STARSHINE, STARBEAM, and STARBRIGHT all failed to improve cognition as measured by ADAS-Cog, ADCS-ADL, and ADCS-CGIC [16].

\section{Intepirdine (synonyms: SB-742457, RVT-101, GSK-742457)}

Intepirdine is a selective 5HT6 receptor antagonist that is being evaluated for use in Alzheimer's dementia and Lewy body dementia. Intepirdine completed phase I trials with no adverse effects. Intepirdine was studied in three phase II studies as monotherapy and one phase II study as an adjunct to donepezil in mild to moderate Alzheimer's dementia. Monotherapy studies showed intepirdine to be well tolerated but less likely to be efficacious in Alzheimer's disease, as the results of these studies were inconsistent. One study showed a statistically significant change in global function but not cognition [17] and the other two failed to show any significant improvement [18], [19]. In contrast, intepirdine $(15 \mathrm{mg}$ or $35 \mathrm{mg}$ ) produced improvements in cognition and ADLs for up to 48 weeks when used as an adjunct to a stable dose of donepezil. However, it did not meet the overall criteria for success with the primary endpoint of Clinical Dementia Rating scale Sum of Boxes (CDR-SB), and did not yield a statistically significant improvement [19].

A six-month, randomized, double-blind, placebo-controlled phase III study called MINDSET was started in 2015 (Table 2). This study evaluated the use of intepirdine $35 \mathrm{mg}$ daily in patients with Alzheimer's disease already taking stable doses of donepezil [20]. In 
Table 2 Phase III Intepirdine studies

\begin{tabular}{llll}
\hline Trial & Formulation & Adjunct & Result \\
\hline MINDSET & Intepirdine $35 \mathrm{mg}$ & Donepezil & Fail \\
MINDSET extension & Intepirdine $35 \mathrm{mg}$ & Acetylcholinesterase inhibitor or memantine & Fail \\
\hline
\end{tabular}

Table 3 Phase III Latrepirdine studies

\begin{tabular}{llll}
\hline Trial & Formulation & Adjunct & Result \\
\hline CONCERT & Latrepirdine $5 \mathrm{mg}$ & Donepezil & Fail \\
& Latrepirdine $20 \mathrm{mg}$ & Donepezil & Fail \\
CONNECTION & Latrepirdine $5 \mathrm{mg}$ & & Fail \\
CONSTELLATION & Latrepirdine $20 \mathrm{mg}$ & & Fail \\
CONTACT & Latrepirdine $20 \mathrm{mg}$ & Memantine & Fail \\
\hline
\end{tabular}

September 2017, Axovant announced that the drug had failed to improve cognition or ADLs. ${ }^{4}$ A 12-month, open-label, extension study of MINDSET using intepirdine $35 \mathrm{mg}$ daily as an adjunct to either an acetylcholinesterase inhibitor or memantine (unspecified) also failed to improve cognition [20].

Intepirdine was also studied in a phase II study in DLB patients (HEADWAY) to compare a 6-month course of 35 or $70 \mathrm{mg}$ intepirdine to placebo in terms of changes since baseline on the CIBIC+ scale. The study did not meet its primary endpoint [21]. ${ }^{5}$

\section{Latrepirdine (synonyms: Dimebon, dimebolin,} PF-01913539)

Latrepirdine, more commonly known as Dimebon, is an antihistamine originally developed for allergic rhinitis. The drug was discovered to

\footnotetext{
${ }^{4}$ More information is available in the entry for intepirdine on the ALZFORUM website: https://www. alzforum.org/therapeutics/intepirdine. Accessed $10 \mathrm{Feb}$ 2018.

${ }^{5}$ More information available in the press release "Axovant announces negative results for intepirdine in phase 2b HEADWAY and pilot phase 2 gait and balance studies; positive trends in efficacy seen in pilot phase 2 nelotanserin study" from Axovant: http://investors. axovant.com/news-releases/news-release-details/ axovant-announces-negative-results-intepirdine-phase2b-headway.
}

have pro-cognitive effects, attributable to its antagonism at the $5 \mathrm{HT} 6$ receptor in addition to the $\mathrm{H} 1$ receptor. Latrepirdine also appears to stabilize mitochondria, making it a neuroprotective drug [21]. Based on these properties, latrepirdine was entered into clinical trials for use in both Alzheimer's disease and Huntington's disease in the 2000s [21].

A small pilot study established latrepirdine to be well tolerated at doses of up to $20 \mathrm{mg}$ TID. A randomized, double-blind, placebo-controlled phase II trial showed statistically significant improvement in five outcomes measured in patients taking latrepirdine $20 \mathrm{mg}$ TID compared to placebo. These outcomes included improvements in ADAS-cog, MMSE, ADCS-ADL, behavior (NPI), and by physician assessment (CIBIC-plus) [22].

Latrepirdine was subsequently entered into phase III trials which included CONCERT, CONNECTION, CONSTELLATION, and CONTACT (Table 3). Latrepirdine was taken with stable donepezil in both the CONCERT and CONTACT trials. It was taken as monotherapy in the CONNECTION trial. In contrast, CONSTELLATION evaluated latrepirdine as an adjunct to memantine. ${ }^{6}$ Phase III trials were

\footnotetext{
${ }^{6}$ More information is available in the press release "Pfizer and medivation initiate two phase 3 trials of
} 
terminated due to a lack of clinical efficacy. Latrepirdine also failed to produce an improvement in phase III trials for Huntington's disease, and its development for use in these two neurodegenerative disorders has since been discontinued [21].

\section{SUVN-502 (company: Suven Life Sciences)}

SUVN-502 is another selective 5HT6 receptor antagonist. Phase I trials showed SUVN-502 to be well tolerated with no adverse effects [23]. The drug is currently in recruitment for phase IIa clinical trials in patients with moderate Alzheimer's disease who are already on stable doses of donepezil with memantine. This trial will be a multicenter, 28-week, randomized, double-blind, placebo-controlled, parallel assignment study. The treatment group includes a low-dose SUVN$502 \mathrm{arm}$ and a high-dose SUVN-502 arm [24]. The drug combination of SUVN-502, donepezil, and memantine will increase the amount of acetylcholine and glutamate in the CNS $[5,25]$.

\section{DISCUSSION}

The 5HT6 antagonists target multiple neurotransmitter systems, including acetylcholine, glutamate, and serotonin. Blockage of the 5HT6 receptor leads to increased acetylcholine and glutamate, which improves cognition. The use of these drugs as an adjunct to acetylcholinesterase inhibitors and memantine supports the cholinergic hypothesis that increased levels of acetylcholine in the CNS promote learning and memory.

The role of serotonin in Alzheimer's disease is not completely understood [2], although its importance in Alzheimer's dementia and other cognitive disorders is becoming evident. In animal studies, overexpression of the 5HT6 receptor has been shown to lead to cognitive impairments, and blocking the 5HT6 receptor appears to promote learning [6]. The 5HT6

$\overline{\text { Footnote } 6}$ continued

dimebon in patients with moderate-to-severe Alzheimer's disease" from Pfizer: http://press.pfizer.com/pressrelease/pfizer-and-medivation-initiate-two-phase-3trials-dimebon-patients-moderate-severe-alz. Accessed 9 Mar 2018. antagonists have also been shown to improve mood disorders such as anxiety and depression that are associated with the progression of Alzheimer's dementia. They would provide the first type of symptomatic treatment available for Alzheimer's dementia [6].

Although current research has focused on symptomatic treatment of Alzheimer's disease, Cirrito et al. suggest a role for serotonin antagonists as possible disease-modifying agents [26]. Their research has shown an association between the use of SSRIs and decreased amyloid-beta plaques in mice. This association appears to translate to human subjects. In retrospective studies, Cirrito et al. found decreased levels of amyloid-beta in human subjects of normal cognition taking a chronic SSRI [26]. These findings support further research into the serotonin neurotransmitter system, especially its relation to Alzheimer's dementia.

The use of 5HT6 receptor antagonists as adjuncts to acetylcholinesterase inhibitors has fostered much excitement, as they successfully completed phase I trials and showed cognitive improvement in phase II studies. Despite their success in the early phases of drug development, idalopirdine, intepirdine, and latrepirdine did not show clinical efficacy in larger phase III clinical trials. The development of this drug class seems to have slowed down considerably, with drugs such as SAM-760, intepirdine, and latrepirdine being discontinued. Idalopirdine may be soon to follow [14].

Despite these disappointing results in phase III trials, it is important to remember that we still do not completely understand the mechanism involved in the 5HT6 receptor or the neurotransmitter pathways involved in Alzheimer's dementia. The 5HT6 receptor is complex and probably has multiple pathways of neurotransmitter communication. For example, both agonists and antagonists of the 5HT6 receptor have been shown to have pro-cognitive effects [6]. Further research will need to focus on the different pathways involved in this receptor system.

As is evident from the failure of the phase III trials of idalopirdine, these medications may also be underdosed. In her review of the drug trials of idalopirdine, Hesselink calls attention to establishing medication dosing in phase II 
trials and the mistake of changing a dosing regime in phase III trials [15]. Although results from STARSHINE, STARBEAM, and STARBRIGHT appear discouraging at first glance, interpretation of this data should be done with care and some skepticism, and conclusions about the utility of idalopirdine should not be drawn until it is tested at doses comparable to those used in phase II trials. Similarly, increased doses of the cholinesterase inhibitors and memantine may be considered.

\section{CONCLUSIONS}

Alzheimer's dementia is a complex disease likely involving multiple neurotransmitter systems in addition to beta-amyloid plaques, neurofibrillary tangles, and possibly other pathological processes. The pathogenic mechanism of Alzheimer's disease is not completely understood. This article reviewed the class of 5HT6 antagonists for use in Alzheimer's dementia. Although phase III trials of idalopirdine, intepirdine, and latrepirdine failed to provide clinical efficacy, phase II trials for several 5HT6 antagonists showed improvement in cognition and ADLs. Further development of these drugs may prove beneficial as our understanding of Alzheimer's disease, neurotransmitter systems, and the 5 HT6 receptor improve.

\section{ACKNOWLEDGEMENTS}

Funding. No funding or sponsorship was received for this study or the publication of this article. Supported by the Barrow Neurological Foundation and NIA P30 AG019610.

Authorship. All named authors meet the International Committee of Medical Journal Editors (ICMJE) criteria for authorship for this article, take responsibility for the integrity of the work as a whole, and have given their approval for this version to be published.

Disclosures. Marwan Sabbagh-stock/ownership: Muses Labs, Versanum, Brain Health Inc.,
NeuroTau. Advisory: Biogen, Lilly, VTV Therapeutics, Axovant, Grifols. CME: MedLearning Group, Miller Meded, Medscape, Rockpointe, Peerview Press. Research investigator: AC Immune, Lilly, Biogen, Merck, VTV Therapeutics, Roche, Avid, Axovant, Janssen, Suven, and Medivation (an investigator for dimebon and Intepirdine). Megan Andrews and Babak Tousi have nothing to disclose. At the time of writing Marwan Sabbagh was affiliated with the Barrow Neurological Institute, Phoenix, AZ, USA. At the time of publication Marwan Sabbagh is affiliated with the Cleveland Clinic, Lou Ruvo Center for Brain Health, Las Vegas, NV, USA.

Compliance with Ethics Guidelines. This article is based on previously conducted studies and does not contain any studies with human participants or animals performed by any of the authors.

Open Access. This article is distributed under the terms of the Creative Commons Attribution-NonCommercial 4.0 International License (http://creativecommons.org/licenses/ by-nc/4.0/), which permits any noncommercial use, distribution, and reproduction in any medium, provided you give appropriate credit to the original author(s) and the source, provide a link to the Creative Commons license, and indicate if changes were made.

\section{REFERENCES}

1. Prince MJ. World Alzheimer Report 2016-improving healthcare for people living with dementia: coverage, quality and costs now and in the future. https://www.alz.co.uk/research/world-report-2016. Accessed 9 Mar 2018.

2. Ramirez MJ. 5-HT6 receptors and Alzheimer's disease (5-hydroxytryptamine 6) (report). Alzheimers Res Ther. 2013;5:15.

3. Anand R, Gill KD, Mahdi AA. Therapeutics of Alzheimer's disease: past, present and future. Neuropharmacology. 2014;76:27-50.

4. Thompson S, Lanctot KL, Herrmann N. The benefits and risks associated with cholinesterase inhibitor therapy in Alzheimer's disease. Expert Opin Drug Saf. 2004;3:425-40. 
5. Nirogi R, Shinde A, Kambhampati RS, et al. Discovery and development of 1-(2-bromophenyl)sulfonyl-5-methoxy-3-(4-methyl-1-piper-

azinyl)methyl-1H-indole dimesylate monohydrate (SUVN-502): a novel, potent, selective and orally active serotonin 6 (5-HT) receptor antagonist for potential treatment of Alzheimer's disease. J Med Chem. 2017;60:1843.

6. Ferrero H, Solas M, Francis PT, Ramirez MJ. Serotonin 5-HT receptor antagonists in Alzheimer's disease: therapeutic rationale and current development status. CNS Drugs. 2017;31:19.

7. Mohler E, Baker P, Gannon K, Jones S, Shacham S, Sweeney J, Ragozzino M. The effects of PRX-07034, a novel 5-HT 6 antagonist, on cognitive flexibility and working memory in rats. Psychopharmacology. 2012;220:687-96.

8. Halford J, Harrold J, Boyland E, Lawton C, Blundell J. Serotonergic drugs. Drugs. 2007;67:27-56.

9. Ivachtchenko AV, Okun IM, Ivanenkov YA, Veselove MS. AVN-322 is a safe orally bio-available potent and highly selective antagonist of 5-HT6R with demonstrated ability to improve impaired memory in animal models. Curr Alzheimer Res. 2017;14:268-94.

10. Ivachtchenko AV, Lavrovsky Y, Okun I. AVN-101: a multi-target drug candidate for the treatment of CNS disorders. J Alzheimer's Dis. 2016;53:583-620.

11. Ivachtchenko AV, Lavrovsky $\mathrm{Y}$, Ivanenkov YA. AVN-211, novel and highly selective 5-HT6 receptor small molecule antagonist, for the treatment of Alzheimer's disease. Mol Pharm. 2016;13:945.

12. Pfizer. Study evaluating the safety and efficacy of PF-05212377 or placebo in subjects with Alzheimer's disease with existing neuropsychiatric symptoms on donepezil. https://clinicaltrials.gov/ct2/ show/NCT01712074. Accessed 10 Feb 2018.

13. Schneider LS. Idalopirdine for Alzheimer's disease: written in the stars. Lancet Neurol. 2014;13:1063-5.

14. Bennett DA. Lack of benefit with idalopirdine for Alzheimer disease: another therapeutic failure in a complex disease process. JAMA. 2018;319:123.

15. Hesselink JMK. Idalopirdine in Alzheimer disease: never change a winning team and do not build exclusively on surrogates. Lessons learned from drug development trials. J Pharmacol Clin Res. 2017;2:1.

16. Atri A, Frölich L, Ballard C, Tariot PN, Molinuevo JL, Boneva N, Windfeld K, Raket LL, Cummings JL. Effect of idalopirdine as adjunct to cholinesterase inhibitors on change in cognition in patients with
Alzheimer disease: three randomized clinical trials. JAMA. 2018;319:130.

17. Maher-Edwards $M$, Zvartau-Hind AJ, Hunter $M$, Gold G, Hopton G, Jacobs M Davy, Williams P. Double-blind, controlled phase II study of a 5-HT6 receptor antagonist, SB-742457, in Alzheimers disease. Curr Alzheimer Res. 2010;7:374-85.

18. Maher-Edwards G, Dixon R, Hunter J, Gold M, Hopton G, Jacobs G, Hunter J, Williams P. SB742457 and donepezil in Alzheimer disease: a randomized, placebo-controlled study. Int J Geriatr Psychiatry. 2011;26:536-44.

19. Maher-Edwards G, Watson C, Ascher J, et al. Two randomized controlled trials of SB742457 in mildto-moderate Alzheimer's disease. Alzheimer's Dement Transl Res Clin Interv. 2015;1:23-36.

20. Axovant Sciences Ltd. 12-Month open-label extension study of intepirdine (RVT-101) in subjects with Alzheimer's disease: MINDSET extension-full text view. https://clinicaltrials.gov/ct2/show/ NCT02586909. Accessed 10 Feb 2018.

21. Sweetlove M. Phase III CONCERT trial of latrepirdine. Pharm Med. 2012;26:113-5.

22. Doody RS, Gavrilova SI, Sano M, Thomas RG, Aisen PS, Bachurin SO, Seely L, Hung D. Effect of dimebon on cognition, activities of daily living, behaviour, and global function in patients with mild-to-moderate Alzheimer's disease: a randomised, doubleblind, placebo-controlled study. Lancet. 2008;372:207-15.

23. Nirogi R, Kandikere V, Mudigonda K, Bhyrapuneni G, Jasti V. Safety, tolerability and pharmacokinetics of SUVN-502-a 5- $\mathrm{HT}_{6}$ receptor antagonist, first in human phase-1 Single Ascending Dose (SAD) study. Alzheimer's Dement. 2009;5:P250.

24. Suven Life Sciences Limited. SUVN-502 with donepezil and memantine for the treatment of moderate Alzheimer's disease-phase 2a study. https:// clinicaltrials.gov/ct2/show/NCT02580305. Accessed 10 Feb 2018.

25. Nirogi R, Ajjala DR, Aleti R, Rayapati L, Pantangi HR, Boggavarapu RK, Padala NSP. Development and validation of sensitive LC-MS/MS method for the quantification of SUVN-502 and its metabolite and its application for first in human pharmacokinetic study. J Pharm Biomed Anal. 2017;145:423-30.

26. Cirrito JR, Disabato BM, Restivo JL, et al (2011) Serotonin signaling is associated with lower amyloid- $\beta$ levels and plaques in transgenic mice and humans. Proc Natl Acad Sci USA. 2011;108:14968-73. 